Sac. Marian BENDZA*

\title{
NATURA UNITATIS ECCLESIAE ET EVENTA ANNO DOMINI 1054 ${ }^{1}$
}

Sic nominata Magni Schismatis Orientalis eventa, in commune consciencia intelliguntur describendum ac describile historicum continuum. Verum est, quia ipsamet eventa plena sunt sindubialis ${ }^{2}$ expressionis, quae immaginationem emovere possunt, sed pro realiter longa perspectiva temporalis amotus, in mentibus hodiernorum Lectorum propriam opportunamque positionem non habent. De cetero, natura horum eventorum in certo sensu descriptam situationem vi improvisa evocavit.

Auctor intendit scribere hunc articulum pro reflexione propria super conglomeratum horum eventorum, praesentare ea volens aspectu tamen theologali, praecipue aspectu ecclesiologiae. Sic monstrata reflexio, de natura rei dogmatica, permittet commune cognita eventa praesentare aliomodo, alia luce ea illustrans, in aliarum relationum contexto.

Sed tamen articulus hic de natura rei historicus est, ideo atque reflexio historica non omittenda esse debet, praecipue cum volemus novam qualitatem cogitandi excitare. Hoc modo, quasi in conjunctione theologia - historia Ecclesiastica, possibili fiet nova relectio horum eventorum sensus, qua eo ipso evocabit novam qualitatem cognoscendi intelligendique protagonistarum actiones et, modestis conditionibus hujus articuli permittentibus, necessim correctionem facere nonnullarum, traditione petrificatarum thesum.

Sine dubio, fundamentum talis reflexionis relatio patristica esset. Scriptis de $\mathrm{X}$ et XI saeculis, monosignificanter crebriterque revelare permittunt non solum continuum eventorum, sed etiam verum, clausum in eis Misterium Ecclesiae, misterium in saeculis velatum, sed tamen infine revelatum!

Revelationis sucursum nominare possimus documentos, anniversarii causa Eventorum 1054 editos. In mente habeo, exempli modo, Declarationem communem (Anno Domini 2004, prima junii), a Papa Joanne Paulo secundo Constantinopolitano Patriarchaque oecumenico Bartolomeo primo, subscriptam.

\footnotetext{
* Sac. professor doctor habilitatus Marian Bendza - Antistes Cathedrae Historiae Ecclesiae Universali et Autocephalicarum Ecclesiarum Orthodoxarum Christianae Accademiae Theologicae in Varsovia; e-mail: mbendza@interia.pl.

${ }^{1}$ Hoc articulus in Latina Nova (Neolatina) scriptus est, primum opus in nova lingua, quae dialectus est Latinitatis.

${ }^{2}$ Sindubialis (neologismus) - dubiis privatus.
} 
Accompanante actui huic congressu, osculum pacis redditum est et gravia verba auscultantur:

„Nostrae [scilicet Orthodoxae Romanocatholicaeque] relationes formatas esse debent vera, profundaque communione in Christo, communione, quae etsi adhuc non plena - jam nunc incipit inter nos unitatis processum. Ideo cum gaudio magno decretamus, quia uniti sumus traditione inseparabilis Ecclesiae, quae semet concentratur in contextu Misterii Eucharistici"”.

Jam hoc praesentatum parvum, sed tamen characteristicum fragmentum, monosignificanter refertur ad naturam Ecclesiasticam, relataque hae, pro gravitate documenti et gradus spiritualis subscribentium huncmet Personarum, non est ad ommittendum.

In hoc documento invenimus omnicognitum, sed in certo gradu controversionem expressum, problema nobis generans: „ecclesiasticae inseparabilitatis” Ecclesiae primo millenio Christianitatis. Estne vere hic periodus inseparabilis? In quali gradu?

De harum quaestionum causa utile videatur denue qualitatem hujus unitatis deliberare, praecipue in contextu Ecclesiae, quae est Communionis Electorum ac Vocatorum. Necessis atque videtur, plus profunda cognitio remonstrandarum „rimarum”, progressu historico in Mystico Corpore Christi factarum. Forsitan utile sit in lucem plenam stare factores parvomodo in historiosophica reflexione respectatos, exempli modo praesentia Normanorum et Historiae ecclesiasticae ipsorum significatio. Talimodo solvendum necesse videtur pro amborum Hierarcharum opinione, quia demonstrata supra unitas insufficiens tamen est. Animadverterunt Ei, atque relationes interconfessionales insufficientes demonstrantur, ideo alio modo debemus rem integram deliberare, invalida elementa ut validemus.

Sed tamen, pro formalis principiis theologiae quam viam eligere, novum falsum non gerendo? De unitate Ecclesiae thesis certo gradu tuta non est, se non omnes aspectus doctrinarum confessionum in memoria teneamus.

Fiat punctum initiale reflexionis nostrae eventum chronologice anterius, plenum theologici sensus, id est Declaratio Communis $(7$ decembris AD 1966), signatarii cujus erant Papa Paulus VI et Patriarcha Constantinopolis Athenagoras. Hoc documentum tertio paragrapho annuntiat:

„Ideo res immense gravis est cognoscere naturam tensionum illis eventis (vel Schismatis Magni) accompanantium [adscriptum expositioque manu mea, M. B.]. Ipsi tensiones adducaverunt progressum eventorum multe longius $[\ldots]$ quam auctores eorum nec intendebant, nec providebant"4.

${ }^{3}$ Papa Joannes Paulus II et Constantinopolitanus Patriarcha oecumenicus Bartolomeus I, Declaratio communis (AD 2004, prima junii), punctum tertium.

${ }^{4}$ Textus Declarationis Communis (7 decembris AD 1966) Papae Pauli VI et Patriarchae Constantinopolis Athenagorae, AAS 58 (1966) 41. Advolvo sacerdoti E. Przekop, Rzym - Konstantynopol. Na drogach podziatu i pojednania, Olsztyn 1987, 49. 
Aliis verbis: Magnum Schisma Orientalis non erat intentio membrorum Ecclesiae saeculi XI, ideo facta est...

Hipothetice hanc sententionem possimus multimodo finire, sed haec situatio non facit nos liberos adaequatam conclusionem formare, conclusionem quae non solum statui facto deliberatae rei coherentem esset, sed etiam sicut in speculo reales, documentis testificatas tendentiones plene demonstraret.

Annorum sexagesimorum saeculi passati animadversio sindubiales tensiones Mediaevales (Declaratio prior) est nobis designatum magnum progressui cogitationis theologicae decadarum proximarum, cogitationis descriptae in Declaratione posteriore:

- Habebantne diversis periodis factae departitiones (vel „rimae” in Corpore Christi) characterem essentialem realitati ecclesiasticae aut non, solum accidentalem?

- Respectantibus tensionibus, possimusne eventa anni $1954^{5}$ tractare stabilem dispartitionem Orientis de Occidente $^{6}$, et in consequentia facta hoc tempore $\alpha \dot{\alpha} v \alpha \theta \dot{\varepsilon} \mu \alpha \tau \alpha$ debita in ambabus confessionibus habere, aut non?

1. Ecclesia in unitate cogitanda de Christo. Videtur, quia gravissimum, ecclesiali aspectu, fragmentum Evangelii est sicut nominata Declaratio Christi, quae est fundamentum existentiae ecclesiasticae, scriptum in Mt 16, 16-18. Hoc fragmentum unum divitissimum fragmentorum theologicorum tractatur pro sua dimensione qualitatis apostolatus, descriptione structuram ecclesiasticam, characteris spiritualis Potestatis demonstratione etc. In hac deliberata pericopa non mancant symboli imaginesque, constructae talimodo, quae atque hodierno tempore ad disputandum theologicum excitant, hac pro situatione controversionem non rare evocant.

E supra citata Declaratione, necessitatum nostrae deliberationis causa,

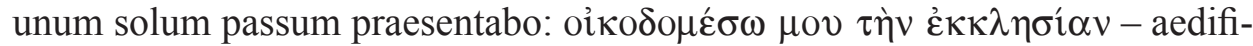
cabo societatem meam, societatem convocatorum (Ecclesiam).

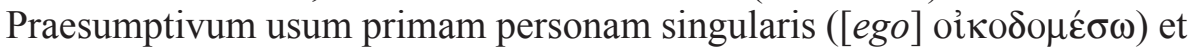
atque in singulari praesentatum objectum ( $\tau \hat{\eta} \nu \varepsilon \kappa \kappa \kappa \eta \eta \sigma^{\prime} \alpha \nu$ ) monstrant, quia in cogitatione Salvatoris existebat una et solum una Ecclesia, quae inspiratione Redemptoris in continuo progressivo „subdita est”, secundum verba Declarationis, Potestati Dei, cui gratia atque Ea fiet taliter fortis, ut omnes portae infernales, quasi sinfortes ${ }^{7}$, nullam iniuriam Ei faciant. Ideo in cogitatione Christi realiter existabit non solum Ecclesia $u n a$, sed decisionibus Dei respectantibus, sola et unica. Ergo: supernaturalis.

\footnotetext{
${ }^{5}$ In homiletico-cathechetica praxi Magnum Schisma Orientale initiale punctum existendi Orthodoxiae in aspectu confessionis tradetur.

${ }^{6}$ Ipso modo ceteram „classici” problematis, S. Runciman et E. Przekop, opinionem dant.

${ }^{7}$ Sinfortes (neologismus) - sufficientibus ad agendum viribus privati.
} 
Hanc supernaturalitatem suggerit atque qualitas hujus continui progressi$v i$ : Ecclesia erit aedificandum secundum constructionem grammaticalem $f u$ -

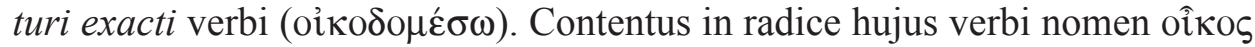
(domus) revocat indirecte non solum naturam hujus aedificandi, sed atque aedificandi effectum. Potestate praesentis ,in medio Ecclesiae” Christi, Domus Dei, sicut anterior Hierosolymitanis Domus Orationis (Beit bit) (cf. Is 56, 7) fiet atque domus constructus omnibus, ubi vel cervis sibi locum inveniet, vel hirundo nidum (Ps 84, 4).

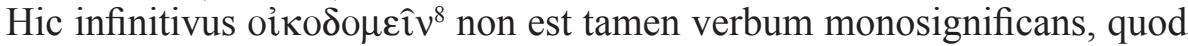
confirmat annis vigesimis saeculi passati editus dictionarius Die Religion in Geschichte und Gegenwart ${ }^{9}$ [Religio in historia hodiernoque tempore]. In conclusione articuli super ipsum thema legimus, quia in Novo Testamento aedificatio non res communitatis est, sed attingit individuum, quod Verbo Dei perfectionante, spirituali labore solum indirecte realitati transvivendi in societate res fidei influat, concentratum est nam super propriam perfectionem.

Ideo, theologicali sensu, supramonstratum infinitivum aliud objectum sequatur, id est „Auctor”. Quis Auctor aedificandi est? Unum solum solvere videtur: ipse Dominus Declarator.

Sunt tamen nonnulli theologici Germanici (id est Kögel Cremerque) ${ }^{10}$, qui inclinantur aliomodo describere Personam Constructoris. Ipsi, Vetero Testamento testificante, monstrant Auctorem Ecclesiae esse debet solum Deus Pater, Qui atque suos confessores alto gratu activitatis donaturus. Cogitationem suam declaratione Apostoli Gentium confirmant, dicentis quia omnis activitas humana in principiali Activitate Aeterna, Activitate Adonai oritur.

Ipse Auctor biblicus in Epistola ad Ephesios imaginem domus - Ecclesiae ${ }^{11}$ utitur in sensu peculiari: sicut Aedificatio de Deo facta. Videtur tamen, quia hoc aspectus insufficiens est pro omissione activitatis hominis. Quod autem invenimus, simul apud Petrum ac Paulum, qui ipsi, sic praedominati eschatologicis ideis plena conscientia aspectum activitatis omittunt.

Ipsa eschatologica imago praesentabitur praecipue post mortem horum Apostolorum, cum desperate defense muri Templi Hierosolymitanis in memoria Templum Novum evocabunt, solum eschatologico modo participantem in apocalyptica Hierosolyma Nova. Lux autem in ea Agnus erit, „Protopresbyter” autem Sedens in Throno, Qui suam Sanctam Liturgiam festivam coram repraesentantibus humanitatis, 144 milia singnatorum, celebrabit.

${ }^{8}$ In Septuaginta repetitur circa 360-ties sicut analogicum verbi bana.

${ }^{9}$ Die Religion in Geschichte Und Gegenwart, 1928, editio secunda, 219. Advolvo P. Bonnard, Jesus Christ edifiant son Eglise, Paris, sine anno editionis, 5.

${ }^{10}$ Auctores dictionarii Biblisch - theologisches Worterbuch der neutestamentlichen Griechish, [Dictionarius biblico-theologicus Graeae Novotestamentalis], editio secunda, 1928; cf. Bonnard, Jesus Christ edifiant son Eglise, p. 6.

${ }^{11} \mathrm{Cf}$. Ph. Vielhauer, Oikodome, das Bild von Bau in der christlichen Literatur von Neuen Testament bis Clemens Alexandrinus, [Oikodome. Imago aedificandi in literatura Christiana de Novo Testamento ad Clementem Alexandrinum], Heidelberg 1939, 190. 
Alteram dimensionem reflexionis apostolicae sanctus Joannes Theologus proponit, eschatologicum aspectum omittendo. Eius apocalyptica imago est una: aedificatio - formatio unitatis cum Agno, cum christianis et cum Patre.

In Declaratione Christi manifestatur atque mandatum unitatis expressum propheta Jeremia: Omnipotens promittit judicium super paganos (Jr 12, 16), quod suggerit solum dimensionem subiectivae unitatis cum Deo et confessoribus amabilem Deo in Israel esse ${ }^{12}$.

In hac sermone sine dubio imago Christi inest immanenter - Lapis aedifi-

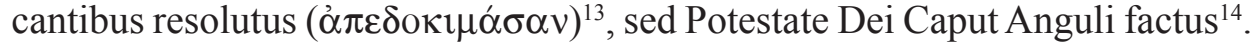
Pro hac causa Christus Auctoritas sindubialis ecclesiasticorum est, sed non sicut solus Aedificator aut Custos Unitatis. Filius enim semper unus est cum Patre, vivens cum Eo in amore, id est in Spiritu Sancto.

Ideo dicens de supernaturali, incomparabili nulli rei Ecclesia Unica, in memoria teneamus relationes in Sanctissima Trinitate praesentes. Sunt enim ii modus Transdonationis Christi de Patre factae aliis, quamquam inferioribus. Veteris Testamenti associationes permittunt atque comprehendere Declarationem Christi elementum novi et aeterni foederis.

Verum est, quia existans jam in Edeno Proto-Ecclesia formabatur in principali contexto amicabilium relationum Adonai cum primis Parentibus, in praesentia quorum poterat Deus promenari Edeni spacia. Haec situatio evocabat gaudium hominis pro Deitatis Praesentia. Et nullus pudicus, nulla nuditas contactos obstabant... Erant nam homines sine peccato.

Sed tamen Christus Ecclesiam Novam annuntiat, ad struendum qualem invitat. Nam Ipse, adimplens Legem verbaque Prophetarum ${ }^{15}$, cum praesentia judaismi Activitatem suam ligat; judaismus nam erit imago continuandi ac adimplendi Dei Plani Salvationis. Ecclesia Ejus erit ideo „supplementum” ac adimplendum Christi sacerdotalis missionis, missionis Templi, quae permittit inventum Abrahae in Petro, qahal ${ }^{16}$ in Societatem Baptizatorum, Israel

${ }^{12}$ Cf. Bonnard, Jesus Christ edifiant son Eglise, p. 13.

${ }^{13}$ Verbum Graecum de terminologia juridica derivatur et falsificatis refertur. Antistites Populi Israelis tractabant Messiam falsificatum; suspiciones habens Hunc inaniter agi despicerunt Eum, in se magnam resposibilitatem pro hoc actu ponens. Atqui erat Jesus Deo utilis nimis Edificator Operis Dei. In margine: responbsabilitas moralis repraesentantium Populi Electi, qui stimulati Antistitium Sacerdotium aut Pharisaeorum decisionibus ad turpe agendum minima est in comparatione „functionarii”...

${ }^{14}$ Eam imaginem revocat Jesus indirecte, advolvens Vetero Testamento. Cf. Mt 21, 42; Mc 12, 10-11 aut Luc 20, 17.

${ }^{15}$ Cf. Mt 5, 17. Praesentatio docendi Christi in contextu adimplendi Legis in Ejus Persona ac activitate Leitmotiv Evangelii secundum Matthaeum videtur. In Christo omnis mesianistica Prophetia finitur. Possumus dicere, quia hoc modo revelantur duae directiones ecclesiastici progressus: una, cujus fundamentum est christologia et altera, fundata in judaistica Traditione, cujus cetere Hic Jesus fidelissimus Commentator fuit.

${ }^{16}$ In Neolatina nomen qahal [societas Judaeorum credentium] indeclinabile est. 
in Populum Electum Foederis Novi ${ }^{17}$. Non insignificans est atque usus futuri exacti, quae monstrat Voluntatem Constructoris conducere opus suum in optimam finem, simili modo tamen confirmans existentiam qualis continui, id est progressus in tempore porrigentis existentiae hujus „organismus fidei”, cuius essentia expressis verbis patefacta in Salvatore non est. Simili modo in silentio Hic tenet tempus initiandi hujus Struendi.

Possibiliter, ,clavis comprehendi” Declarationis Salvatoris de parte Apostolorum (discipulorum $)^{18}$ in colligatione cum quahal inventa est. Unitas et qualitas organisationis hujus societatis de natura rei imago est organisandi Operis Christi. Ideo, etsi exceptionalitas ecclesialis certa est, in sensu organisationis repraesentat Ecclesia exemplificationem qualitatis existentium in Plenitudine Temporis religiosarum formarum.

Hoc modo formata Ecclesia semper ad Christum appellans, absolutam perfectionem in continuo struendi numquam attingit. Talis perfectio possibile fiet tum denique in Regno, ubi Jerusalem coeleste, cujus lampas est Agnus (cf. Ap 22, 5), Jerusalem quod fiet salvatis ,portus recreationis”.

Existat tamen quaestio aperta, minime difficilior prioribus, qualis est relatio inter Antiqui Foederis periodum formandi Ecclesiae et periodum Testamenti Novi. Theologia Romanocatholica, generaliter dicens, assertat clare, quia denique contextus Oblationis Christi et temporis Pentecostes permittit dicere de ecclesiali existentia par excellence ${ }^{19}$. Ideo videtur Vetus Testamentum solum typologice tractandum sicut forma praeparativa Testamenti $\mathrm{Novi}^{20}$.

Talem opinionem comminuit tamen analysis qualitatis qahal phaenomeni, existantis millibus annis. Possumusne tale longum periodum solum indictionem tractare? Sine dubio sic. Arca Foederis erit semper typus Sanctissimi et Noe Arca typus consecrationis baptizmalis.

Existant tamen designata semiologica plus importantia quam typologia, exempli modo: cathegoria Populi Dei, autopraesentatio Israelis Gregis Domini, messianica dimensio fidei, theologia spei, regulariter practicata pietas biblica, „custodia institutionalis” Veritatis Dei etc. Hoc tamen elementum, quod haec designata colligit non solum fides est, sed ante omnia conscientia hominis credentis. Ipsa conscientia fundamentum est constructionis Ecclesiae, praecipue tamen educationis dimensione.

${ }^{17}$ Cf. Bonnard, Jesus Christ edifiant son Eglise, p. 25. Hic Auctor, referens ad praesentatam interpretationem Construendi Christi, nominavit eam „revolutionalem”.

${ }^{18}$ Omnis Evangelista Apostolos discipulos nominat.

${ }^{19}$ Hodierno tempore Magisterium Romanocatholicum inclinatur praesentare Pentecostes tempus manifestationis jam existentis Ecclesiae, in silentio tamen tenetur tempus initiale hujus existentiae. Declaratio Jesu non poterat esse tempus initiandi, etsi Verbum Dei creavit coelos ac terram, quia Salvator dicit de Ecclesia in futuro. Certissimum solvendum problematis oblatio videtur - in Cruce et in altare...

${ }^{20}$ Cf. J. Laska, Kościót, Eklezja, Chrystus, Warszawa 2012, manuscriptum [proprietas Auctoris], 26. 
Confessor judaismi in periodo ante Plenitudinem Temporis, conscientiam suam formabat super fundamentum Nationis. Omne membrum, Populo Electo ente cognoscit, quia electio ejus via erat ad absolutam Electionem Dei, omni sabbato synodusque in synagoga supplementum peregrinationum ad Templum. Societas credentium formavit Adonai quamquam directe, rhytmum viae ejus peregrinationibus sophar sono ardinans. Adonai, Petra Salvationis monstravit tamen omnibus quidquid majus: Adventum Messiae, adventum Epochae Novae.

In quali gradu „Epochae Novae” erat tamen incognitum mentibus Magistrorum. Ideo attendenda fiebat clara, perspicua omnibus signa, praecipue colligita cum reflexione biblica: Elian, Ignem, Diem illam... Erant attamen multi, qui atque nunc fundamentum vitae religionis in peregrinationibus sophar sonique videntur, sed...

Hoc momento ad aures eorum attingit Declaratio: „Tu es Petrus [...] et super hanc petram aedificabo Ecclesiam meam” (Mt 16, 18).

Haec imago confessori judaistico in memoriam revenit struendum Templi Davidi - Salomonis, illo tempore restauratum a Herode. Sed veritas apparuitur major quam Templum, major Salomoni ${ }^{21} \ldots$

Declaratio struendi est atque transdonatio dynamismi Christi in movendum hunc processum. In contexto hujus dynamismi incipiebatur novus actus Creationis Hominis Novi ac Novae Realitatis. Haec realitas optime illustrat imago Agni, quae Christus est, Cuique sunt omnia imagine germinis praesentata.

Unitas Ecclesialis est igitur multigrada et multidimensionalis. Ligamentum cum Christo est, ligamentum amoris fidelibus; unitas in Gratia et societas in Verbo; unitas sacramentalis et fides individualis.

Orthodoxa visio hujus unitatis duo aspectus habet: theologicum et canonicum. Theologalis comprehensio unitatis fundamentum suum in confessione Trinitatis Doctrinae, formatam conciliariter ${ }^{22}$ dum septem primis conciliis generalibus invenit. Concorditer magisterio sancti Pauli, praesens in omni mundo visibilis Ecclesia „organismus” est constructus de ,autocephalicis unitis”, autonomicis societatibus confessorum, Ecclesiis localibus, quae omnes invicem plenitudinem (pleromam) constituent in fundamento amoris.

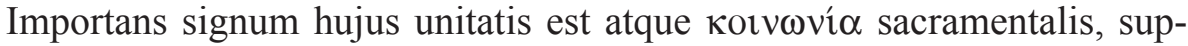
porta acceptatione integraliter comprehensi Revelationis et atque realisatione vitae Ecclesialis in societate (convocatio synodorum liturgicarum, concilia etc. $)^{23}$. Haec reflexio ad biblicam imaginem ecclesiologicam refertur:

- Unus Dominus, una fides, unum Baptisma - Eph 4, 5;

- Etsi nos aut Angelus de coelo nuntiaverit vobis aliud Evengelium quam nosmetipsi, anathema sit - Ga 1,8.

Unum est enim Magisterium Domini, Evangelium.

${ }^{21}$ Ibidem, p. 27.

${ }^{22}$ Principium sobornosti - conciliationitatis.

${ }^{23}$ In conceptione Romanocatholica praecipue unitas confessionis fidei et unitas sacramentalis explicitur. 
Confirmatio hujus traditionis in sermone sancti Irenaei invenimus: vera et catholica Ecclesia unam ipsamque fidem in mundo integro conservat ${ }^{24}$.

Unitas in sacramentali dimensione fortiter dirigitur ad spiritualitatem. Sit confirmatio hujus rei avvolutum: „Accipite Spiritum Sanctum. Quorum remiseritis peccata, remissa sunt eis, quorum retinueritis, retenta sunt (J 20, 22$23)^{25}$. Hanc situationem confirmat atque sanctus Hilarius: uno dono sacramentali omnes uniti sumus ${ }^{26}$.

Possumus ideo dicere, quia visibilis unitas „retorsio” est internae, invisibilis unitatis in Spiritu Sancto. Illa unitas ligas nos praecipue cum Christo, cum sororibus fratribusque, et vincula hujus unitatis irrompibilia videntur.

Effectu „contrapositionis” duorum conceptionum - ecclesiologiae sacramentalis (praecipue in Eucharistica dimensione) ${ }^{27}$ et ecclesiologiae universalis ${ }^{28}$ communio cum Christo videtur in Ejus Coena et Oblatione. Eucharistia, coronatio initiationis christianae est enim fundamentum Ecclesialis Existendi, etsi vita sacramentalis in conditionibus ecclesiasiticis fiet sui generis novum, praecipue in contextu dimensionis integritatis. Ecclesia enim semper continuanda, semper manens in Eucharistia ${ }^{29}$, semper „,fortificata” Christi unitate.

In memoria atque teneamus gravis significatio dimensionis antropologicae, expressis verbis concretizatae in deliberato passu Mt 16, 18: spatium ecclesialis struendi est homo. Petrus - petra repraesentare videtur omne genus humanum, cui in certo modo transdonatum est privilegium misterii constructionis.

Eo modo Christus in primo plano stat quaestionem personae, persona enim conducere ad finem cogitationem operis Christi debeat. Advolvens ad Boëtium $^{30}$, persona rationalis naturae individuae substantia, id est unica forma existendi naturae rationalis. Latinum adiectivum individuus significat unicum separatum, sed ante omnia unicum autonomicum. Ideo Christus, construens Suam Ecclesiam facit Eam ,proprietatem” suam, etsi transdonavit hominibus

${ }^{24} \mathrm{Cf}$. Irenaeus, Adversus haereses I 1, 10.

${ }^{25}$ Secundum Vulgatam Novam papae Pauli Sexti.

${ }^{26} \mathrm{Cf}$. Hilarius Pictaviensis, Commentarius in Psalmos 1, 21, 5.

${ }^{27}$ Videtur res necessitas advolvere commentario Romanocatholico de initio XX saeculi: [Talimodo status unitatis] ,consequentia est naturae societatis visibilis, quod est Ecclesiae. Sacramenta Sancta sunt enim visibilia media sactificationis, et quis digne ea utitur, certus essere potest, quia in actu accipiendi ea, Deus dat ei Gratiam invisibilem; se autem diversa genera mediorum hujus non existerentur, nemo sciisset qua uti debet et sine dubio utilibilis esset omnia aut, in contrario, omnia tractravisset rem tote indifferentem. Exempli causa non gravis esset forma visibilis aut informa actus accipiendi Corporis Domini Jesu in Sanctissimo Sacramento" (Cf. J. Tylka, Dogmatyka katolicka [Internet versio sine datibus editionis: www.opoka (20 X 2014)].

${ }^{28}$ Primis saeculis Ecclesiologiam eucharisticam praesentabant Patres et Doctores Ecclesiae Orientalis, exempli gratia sanctus Ignatius Antiochenus. Repraesentantem cogitationis occidentalis putare possumus sanctum Hipolitum Romanum Ciprianumve de Carthagine.

${ }^{29}$ Cf. P. Evdokimov, Prawostawie, Warszawa 1986, 164.

${ }^{30}$ Boëtius (480-524), philosophus Romanus; suam famam definitionem personae includit in opere De persona Christi (PL 64, 1343). 
possibilitatem desideratae autonomisationis, quae procedit de personalistica individualitate aut atque de tendentionibus separatisticis.

Sic vidimus, unitati ecclesialis contrastitur „unitas autonomica”, „unitas entium autonomicorum". In contacto cum mysterio Christi fictica paradoxis unitatis in separatione fiat realitas logica: persona autonomica jus habet interagere cum mysterio Unitatis Dei, participat enim hoc modo in Trinounitate possibilem faciens modum progressus sui. Ne obliviscamur atque, quia realitas Trinitatis summa existentia est, atque ipsa characterizans se autonomicam. Dicimusne de Hipostasi Patris, Hipostasi Filii aut Hipostasi Spiritus Sancti? Ideo ecclesialis participatio in Mysterio Dei autonomismus characterizat, praeter quo Deus creat cum credentibus unitatem, permittens iis personalem libertem et transparentionem electionum conservare.

Ideo, in libera rationalisque autonomia personae qualitas ,trigradualis unitatis" interpretatur. Interpretata est unitas, unicitas et exceptionalitas Ecclesiae omnes tres jussu Dei non separabiles, sed coëxistantes modo accibile simul Deo et homini.

Accuratio qualitatis autonomicae unitatis hujus non insignificans est pro fluctuationibus dynamismoque ecclesialium. Dicere potitur, quia electiones hominum declarantur non solum in adveniendo aut abeundo, sed atque in egoismo. Tan qualitatem electionum invenimus ideo de natura rei in ,organismis ecclesiasticis", et hae electiones querelas et discussiones evocant super themate modi functionandi Ecclesiae. Nemo scit, quid gravissimus esset: oratio laborve charitativus, forsitan docendum? Omnes tres videntur in essentia sua et vere sunt atque elementa constructiva, sed Jesus admonit: Miseros semper inter vobis habetis, sed Me non semper (Mt 26, 11; cf. atque: Mc 14, 7; J 12, 8). Hoc significat, quia nostra communio cum Christo potest dirrompi, cum malo effectu atque hominis existentiae in Ecclesiastico aspectu, dum pauperes et ligata cum eis actio charitativa, sine dubio pretiosa et gravis, praesentabit clare suan ,inessentialitatem" pro realitate Ecclesiali, non tan essentialem quam vita sacramentalis aut annuntiandum Doctrinam Domini. Quod magis, haec praesentatio demonstrat atque characteristicam realitati existentiae humanae possibilitas decisionalis: ab- aut reveniendi.

Ideo continuum Ecclesiae significatur facticis fluctuationibus. Liberum arbitrium potem simili modo causare declaratio pro Christo aut electio rerum Ei contrariarum. Vos atque abire voletis? - demandare videtur Deus. Et haec quaestio semper repetens verificator dynamismi vitae christianae est, sublimiterque characterisans momenta vivendi Ecclesiae „extra Christum”, cum „orationem tenet” egoismus, aversatio, inamabilitas, aut spiritualis amotus de Spiritu Christi ${ }^{31}$.

${ }^{31}$ Breve, etsi verisimiliter non de omnibus Christianis idem sentitum descriptum realitatis Ecclesiae inest in S. Runciman libro Schizma Wschodnia: „Tactus et moderatio sunt in optimo casu rare videtae in ecclesiasticis circulis, et se deerint pro ignorantia, effectus possunt tragici esse" (Schizma 
Scimus tamen, quia unitas semper renovabilis est in Spiritu quia, sicut dicit sac. H. Paprocki ${ }^{32}$ fluit ea de Unitate Dei; Ecclesia non est enim multitudo personarum in earum separatione, sed in unitate Gratiae Dei, vivens in multitudine rationabilium creaturarum, ante hanc gratiam genua flectantium.

Qualis ideo est dimensio unitatis ecclesiasticae in aspectu doctrinali?

Videtur, quia ipsa est cathegoria absoluta, praecipue in contextu unae fidei, unius Baptismatis, unae Eucharistiae, et ante omnia Unius Christi. Una est atque Veritas et Unum Regnum, descriptum Veritate. Sic contextualisata Ecclesia est unicum phaenomenum unicae, indivisae, sed autonomicis ,elementis" constructae societatis, ubi Deus est omnis in omnibus. Ecclesia, effectu indirecti „tactus” manus Salvatoris, in duobus fundamentis construitur - in amore Dei et in amore proximi, ut eo modo Haec fiat realitas tan soteriologica, quam eschatologica.

Unitas et „unicitas” speciali modo campus est agendi Christi colligati cum Patre, de Quo accepit omniam potestatem in coelo et in terra (cf. Mt 28, 18). Hic Christus in Sacramentis realisat mandatam Ei Patre missionem intercessionis sacerdotalis Gratiae.

Principium unitatis est atque Spiritus Sanctus - Ecclesia est enim societas convocata de Spiritu, semper agentis et adjuvantis curriculum ecclesiasticorum eventorum ${ }^{33}$. Gratia Ei prophetia, ascesis, mystica, charismata coronant realitatem ecclesiasticam, significans atque autenticas vias salutis sanctificationisque $^{34}$.

Unus est conflatus unius Spiritus, gratia Cui creata est Scriptura. Scripturae Sanctae auctor (vel melius redactor), nullam rem accepit praeter propriam formationem educationis, aptabilis tamen Spiritu Sancto factus ad vere annuntiandum Veritatem Dei.

Spiritus Sanctus creat atque Corpus Christi - Ecclesiam visibilem, colligatam cum Ecclesia Invisibili, conagens cum Ea in realitate sacramentali et continuans Christi Struendum. Sicut dicit sac. Paprocki: ,in descensione Spiritus, existata Ecclesia sicut Corpus", et atque Spiritus conditio plenitudinis vitae in Deo est ${ }^{35}$.

Gratia Spiritui una est atque fides.

Unum baptisma...

Et una spes Eschatonis.

\footnotetext{
Wschodnia, Warszawa 1963, 20). Simul Auctor hujus characteristicae, ac ejus Receptor faciliter conspicit, quia haec verba apta sunt ad characterisandum eventa Anni Domini 1054.

${ }^{32}$ In articulo Granice Kościoła, [Internet versio sine datibus editionis: www.prawosławie.pl (20 XII 2014)].

${ }^{33}$ Sed atque Hic potest simul cum Christo esse repudiates...

${ }^{34} \mathrm{Cf}$. Paprocki, Granice Kościoła [pro Internet versione desunt numeri paginarum].

${ }^{35}$ Ibidem.
} 
2. Unitas ecclesialis in continuo progressu. Persona humana praesens participansque in Mysterio Dei, fundamentum generat existentiae Ecclesiae visibilis in dimensione temporali, ubi divitiae realitatis Doctrinae „collidunt” cum conditionibus terrenis.

Antea, probabiliter jam apostolicis temporibus, sed certissime de IV saeculo, historiam Ecclesiasticam praedominantur fluctuationes humanae. Dominanta historiae fiunt non solum individuum peccatum, sed atque spectacularia et effectu gravia eventa, frequenter non coexistentia cum vita Ecclesiastica (exempli gratia translocatio sedis Caesareae de Roma ad Bosphor) ${ }^{36}$. Eventa hae causabant non solum mutationes in mentalitate, sed generabant legendares quamquam interpretationes, legitimizantes talem, et non alium, hominibus generatum rerum statum.

Cursus primae decadis saeculorum historiae Christianae, in postera historiographia ${ }^{37}$ characterisatus est „Christianitatem indivisam”. Generaliter hac res inacceptabilis videtur, quia praesentata eventa confirmant tote aliam situationem: jam temporibus apostolicis facta divisio erat vis progressiva Ecclesiae. Vis hac revelavit suam praesentiam in secunda millenario Christianitatis, quando ceterum cognita de Christo elementa autonomisationis personalisticae fiunt quasi fundamenta vitae ecclesiasticae. Hoc modo theologia reveniendi ad Deum et laborandi super ,deflationem” fluctuationis substituebatur certamine sacri contra mundialem, humanum. Figurative dicens, in initio XI saeculi humilitas et Kenoza Christi contactibilis fiebatur tendentionibus facilitatis propitii curaque sui et suae familiae.

Hoc modo fluctuationes principaliter concentrabantur super primatum ambarum Sedium et qualitatem relationes earum in contextu conservationis et praesentationis unitatis.

Verum est, quia hoc primum millennium, ,pietatis pneumatologicae" causa non disponabat tali gradu, quam millennium proximum, possibilitate ad separandum. Sine dubio, factor principalis unitatis hujus erat colligatio visibilis dimensionis Ecclesiae cum indiviso judaismo ${ }^{38}$ et principaliter tractata unitas cum visibili apocrisarii Petri et repraesentantis Christi in terra, id est cum Papa $^{39}$. Secundo millennio, praecipue post assedium Constantinopolis

\footnotetext{
${ }^{36}$ In Latina nova Bosphor indeclinabile est.

${ }^{37}$ Praecipue in historiographica vetus-catholica.

${ }^{38}$ Cujus confessores ceterum, in circumjecto pagana viventes, sentiebantur se sicut ,separati” de aliis, facti Electionis causa, et praecipue monoteismi practicatae fidei.

${ }^{39}$ Hujus repraesentationis fundamentum erat conditiones historiae laicae: importantissimi Patriarchati facti sunt patriarchati capitales, quamquam altera tres (in pentarchiae aspectu) sancticati sunt apostolica in iis praesentia, et Hierosolymam superavit atque praesentia Christi Ipsius. In margine addemus, quia Patriarchatus Hierosolimitanis de temporibus patriarchae Focii et Papae Nicolai non consideratus erat in catholicismo Romano Matrem patriarchatorum, mutatis nominibus Hierosolymis in Aeliam Capitolinam. Pro nulla existentia Hierosolymis impossibilis factus est atque Patriarchatus Hierosolymis. Hoc non significat, res clara, negationem Urbis Sanctae locum agendi Domini, sed magis juridicum, non ideologicum punctum videndi.
} 
anno 1204, ultimum assedium et destructionem ejus in 1453 significata fiebant elementa hostilitatis, resentimentorum, interrompentes prior existentem ideam unitatis Orientis cum Occidente.

Sicut videtur, constituens elementum Ecclesiasticum, unitas, conservata erat simili gradu primo ac secundo millenio, tamen actiones antropologicae efficiebant ,personalistica dominante separationis”, colligata de natura rei cum persona humana. Haec situatio generavit novam qualitatem conditionum.

Maxime visibilis et nos delectans conditio est „politica” separatistica Orientis de Occidente, dirigans ad „schisma” patriarchae Cerularii, „signum ultimum" existentium de saeculis tendentionum. Talis status consideretur „praeparationem” status posterioris, status polarisationis extremalis.

Atque analysis generalis permittit videre Ecclesiam Orientis Ecclesiam Caesari, dum Ecclesia Romana Ecclesia Papae videtur. Ab initio existendi harum diversarum conceptionum Ecclesiologicarum stat sicut factor principalis translatio anno 330 sedem Imperii ad Constantinopolem, situatum in liminibus duorum continentorum, transfiguratum posterior in urbem maxima significatione strategica et oeconomica ${ }^{40}$.

Regio occidentalis transmutata tamen est in campus invasionis alienorum aut in locum commovendi alienarum idearum aut novae methodologiae theologicae. Hoc modo situatio confrontationis constituta est: magnalia versus antiquitatis ambitionis vestigia. Naturalis consequentia erat orientalis oscillatio.

Oscillatio haec postulat seriosum valde in reflexione theologica tractandum, se Constantinopolis, locus quattuor conciliorum superat ambitione Romam antiquam ${ }^{41}$, sine dubio ipsa debet atque in dimensione ecclesiologica accipere possibilitates datas ei decisionum politicarum via.

Finitum in 381 anno Concilium Constantinopolitanum Primum, in canone tertio decidit tamen, quia sedes in Bosphor pro traditionis, lungae historiae ac qualitas agendi causa, occupare debet secundum, post Romam, locum, non primum ${ }^{42}$. Talis tractatio non sublationis novam sedem causa, sed pro confirmatione conditiones historicas, facta est. Primatus Veteris Romae confirmavit atque canon 28 Concilii Chalcedonensis cum additione tamen, quia privilegia divisa esse debent uno modo de ambabus Sedes ${ }^{43}$.

Talis situatio jam in initio generat problemata doctrinalia et lites culturales, liturgicae et organisationis super practicas religiosas, celibatum etc... Distantiam majorisabant distinctiae linguisticae ${ }^{44}$ et ante omnia quasi „classica” discussio de Filioque...

\footnotetext{
${ }^{40}$ Cf. Przekop, Rzym - Konstantynopol, p. 17.

${ }^{41}$ In memoria teneamus, quia Romae nullum in antiquitate concilium oecumenicum locum suum tenebat.

${ }^{42}$ Cf. Runciman, Schizma Wschodnia, p. 22. Cf. atque Przekop, Rzym - Konstantynopol, p. 17.

${ }^{43}$ Cf. Przekop, Roma, p. 17.

${ }^{44}$ Praecipue criticabantur linguas slavonicas, quas usantur in actione missionaria.
} 
Lites hae frequenter mutabantur in diversas formas concurrentionem Papae Romani cum Patriarcha Constantinopolitano. Concurrentio haec erat ,signum magnum" historiae Christianitatis Europensis, sed non tangebat essentiam Ecclesiae. Et haec essentia erat unitas.

Ipsa declarabantur cetere in dimensione visibili: sancti Cirillus et Methodius missi de Caesare Byzantino ad Slaviam subdiderunt se atque jurisdictioni Papae, et Bruno de Querfurt, suam missionem inter Pietsingis realisans, commodum accepit de principe ruso, baptizato in ordine graeco...

Possumus dicere, quia praesentata supra idea unitatis, existit independenter de iis difractionibus et quasi apud eas, quamquam graves hae erant, existens partim sicut eventa, partim sicut tendentiones, quae non solum risas, sed atque disrumptiones in Mystico Corpore Christi generabant. Non erat hoc tamen schisma, ne quidem discidium, sed difficultates in continuandi prioris status relationum interconfessionalium, quae non erant harum relationum disrumptio ${ }^{45}$.

Conscientia in themate discidii semper praeerat inter confessoribus jam ab initio XI saeculi. Hi confessores viderunt atque colligantem eos unitatem monolithum nullum et nullam sculpturam una indivisa massa auri factam. Confirmationem talis status rei invenimus in conservato documento chartophylacis byzantini, Nicetae de Nicaea, cujus titulus characteristicus est nimis: Quibus temporibus et quarum criminationum causa a Constantinopolitana Ecclesia sejunxerit se Romanorum Ecclesia ${ }^{46}$.

In hoc satis amplo opere auctor ejus monstrat diversas formas schismatum discidiorumque, facta praecise in primo millenario Christianitatis. Monstremus gravissima eorum:

a) Tempore Leonis Magni „rursus sciderunt se Romani, et ab imperio Constantinopolitano, et ab ejus Ecclesia, abjecta subiectione atque unione foedusque injerunt cum Francis, deficiente simul universa Italia. [...] Denique pseudo patriarcham Anastasium anathemati subjecit Gregorius" ${ }^{47}$. Hoc modo auctor praesentat discussionem dogmaticam de monophisitismo et commandatum in hac causa documentum cum destinatione ad Patriarcham Constantinopolis Tomum ad Flavianum. Patriarcha Flavianus in concordia erat cum Papa in Christo duas naturas sed unam Personam esse, quamquam contrastabat tali statu rei abbas Eutiches, qui in effectu revocatus de officio est. Eo ipso „situatio belli" initiabatur. Caesar Theodosius convocavit anno 499 concilium ad

${ }^{45}$ Hoc modo, se dicimus de separatione Acatii aut schismate Focii non soleamus criteria contemporanea, exempli gratia de tempore Renascimenti uti. Decisio sacerdotis Martini Luther aut aliorum reformatorum omittebat essentiam Ecclesiasticam, se concentrans in modelis antea incognitis, de ipsis reformatoribus factis. Fundamentum ideae unitatis erat eo tempore primatus Papae Romanae. Bella cum primato non erat initiata - hunc problema dissolvabantur discussione.

${ }^{46}$ Textus conservatus solum in linqua Latina, PG 120, 713-720. Etsi documentum grave est, auctoritas ejus tamen est dubitalis. Certissime, quia hoc opus non fidele caesari chartophilace Niceta Chomiate (1155-1215) scriptum est, sed verisimilius de alio historico (aut aliis historicis) Occidentali.

${ }^{47}$ Ibidem, PG 120, 716. 
Ephesium, antistes cujus patriarcha Dioscurus erat. In consequentia Flavianus revocatus de officio, in tribus diebus torturatus.

Papa Leo I praesentavit hoc tempore formulas dogmaticas praecisiores formulis de Ecclesia Orientali praeparatis, super quales laborabat Cirillus Ale-

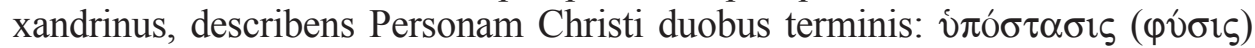
- caro. Sed Leo Magnus tria termina usus est: Verbum (Persona Dei) et duae naturae - divina ac humana. Talis status doctrinalis praesentatus est in Tomo, fundamenta declarationis cujus solum scripturisticis et principaliter tractatis dogmaticis formulis de Tertuliano ad Augustinum de Hippone confirmantur.

b) Tempore Caesaris Zenonis separatio Acatii ${ }^{48}$ occursit. Ipsa erat continuatio discussionum monophisiticarum. Separatio haec duravit anni 484-519, et causae ejus erant diversae, praecipue tamen resistantia contra partem Cristianitatis Orientalis ante acceptationem canones quarti Concilii Oecumenici. Documentum grave de hoc periodo Henoticon aut Actus Unitatis est, ubi legimus, quia fundamenta fidei Christianae solum in primorum trium conciliorum decretis inerant, anathema tamen omnibus alio modo cogitantibus.

Conjunctio Orthodoxiae cum monophysitis significabat contrapositionem coram Papa Romano, sed „schisma” finita est brevi tempore, dum Caesar Justinianus declarationes concilii Chalcedonensis accepit.

c) „Sub Photio, Constantinopoleos patriarcha, magnum erat schisma, multaeque Romanis crimina indictae fuerunt"49.

d) Post longius tempus, dum dominavit Monomachus et patriarcha Constantinopolitanensis, Cerularius facta est in Oriente tota separatio, cum rememorabantur priores conflicti cum Latinis, qui in vendictae actu nomen Papae de sancto Dyptycho demoverunt ${ }^{50}$.

De patriarcha Fotio multa jam opera scripta sunt, ideo in articulo additamentale sufficit solum breviter de ipso scribere, sed thema quaestiones Cerularii tenor reflexionis nostrae.

Generalibus analysis factis, imaginem idealem construere possimus: ecce optimus Papa et pessimus Patriarcha Byzantinus. Papa nullam bellum convocat, Patriarcha tamen in malanimitate sua semper hostem Romae videtur. Posteri omnia intelligens, solum problemata unionis in mentibus habentes, suis temporibus magis magisque ea cognoscere cupiunt.

Omnes tamen non negare debent, quia tamen de ambobus partibus ,,conflicti", nec deerant horribilia, nec non miscomprehensiones. Operum praetium atque est, quia periodus primi millenii, tempus formationis et creationis reflexionem dogmaticam debeamus nominare. Hoc tempore melioris cognoscendi Deum multis ac diversisque modis operam dabant theologi christologicas praecipue quaestiones, fundamenta fidei optime ut cognoscere. Homo errabilis

\footnotetext{
${ }^{48}$ Cf. ibidem.

${ }^{49}$ Ibidem, PG 120, 717.

${ }^{50} \mathrm{Cf}$. ibidem.
} 
est, ideo non mancabant illo tempore errores, sed sine iis impossibile videtur realisandum viam ad Veritatem.

Nonminus, cum analysim facimus epistolarum aut aliorum documentorum epochae facitur, reales fractiones negare non potitur. Operum praetium tamen videtur quaestio de qualitate sindubialium fractionum.

Mundocognitus expertus in causis Orthodoxiae, prof. D. Obolensky, in diversis occasionibus repetebat, quia essentialis causa fractionum erat aspirationes in ambobus partibus conflicti. Papae Romani, dirigentes optimum illo tempore progressum Reformae Gregorianae, prioribus probis observatis et Oriente acceptatis, operam dabant non solum voce consultativa servire, sed etiam dominare cogitationem orientalem aequo modo aspectu fidei ac mentalitatis. Oriens autem, suam certam prosperity atque in sensu theologico transvivens, non videbat necessitatem ejurandi primatum.

Vellim tamen vi magna accentare praesentatas relationes par excellence schisma non esse, schisma comprehensa sicut fractio credentium motusque autonomisans aut tendentio creandi organismum separatum ecclesiali charactere. Nullus protagonista, in his eventis participans, erat schismaticus, quia omnes uno Baptismate significati erant, nullique volebant fractiones generare, ignem eventualium litium privato modo in silentio extinguere.

Non insignificans est atque factus existendi hujus fractionis sine dubio de facto (pro qualitate mentalitatis confessorum), sed non de jure, quia nullum schisma in canonico sensu existerint ${ }^{51}$.

Ad illustrandum hanc quaestionem utile videtur paene incognita, bella Graeca scripta Epistola Dominici patriarchae Venetiarum ad patriarcham Antioche$n_{n^{5}}{ }^{52}$. Revocatio hujus documenti permittet nobis recognitionem causae alio modo praesentatam, quam in scriptis creatis de Papis, Patriarchis antiquitatis aut Caesaribus. Patriarcha Venetorum honorabili modo fungebatur, antistite de facto ente parvae, quamquam gravis, cum magna historia, dioecesiae.

Epistola, mentionem cujus fecimus, initiatur introductione, in qua descriptio ejus characteris contenta est:

„Admonemus, omnis desiderii ac reverentiae voto, cum proposito fidelissimi obsequi, nostrae reverentia et amicitia honorari et coli Ecclesiam Tuam, quae nostrae matris Romanae Ecclesiae soror esse $\operatorname{cognoscitur}{ }^{53}$, atque fundatoris

${ }^{51}$ Gravis est atque factus, ambas partes se geresse tranquiliter et in moderatione.

${ }^{52}$ Cf. Epistola Dominici patriarchae Venetiarum ad patriarcham Antiochenum, PG 120, 751 756. Romanocatholicus patriarchatus Venetiae, quia sic nomen obligatum est atque hodierno tempore, generatus fuit anno 774 non grandem dioecesem. Pro gravi significatione urbis, episcopi Venetiani cathedrae Sancti Marci honoratum privilegium tituli patriarchalis acceperunt, quo tamen initio XI saeculi repositur. Anno 1091 generata erat dioecesis Castello, quae anno 1451 colligata de VI saeculo existanti patriarchato Grado est, generans hoc modo unum organismum administrativum, restituens atque usum tituli patriarchae.

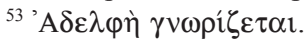


sui meritis, Patri videlicet apostolorum omissis ${ }^{54}$, fama pietatis tuae, fide ac opere plene ipsam se ubique proclamans, cogit nos humilem tibi reverentiam reddere, necnon te per viam Domi incedente, vestigia tua sequi" ${ }^{55}$.

Patriarcha Venetianorum alio loco tamen admonet:

„Attamen hoc paternitati vestrae facere non possumus, quod a clero Constantinopolitano sanctam Romanam Ecclesiam vituperare audivimus. [...] Itaque redargui debent a vestra paternitate, qui adeo impudenter Sacris Apostolicisque sanctionibus contradicunt; et in quo aedificare arbitrabitur, non solum aedificata destruunt, sed ad fundamentum ipsum effodiunt. Frustra quippe beatissimi Petrus et Paulus in Italia praedicarunt, si Occidentali Ecclesia, beatitudine sempiternae vitae privatum, ad quam nemo perveniet nisi particeps fuerit Corporis et Sanguinis Christi, sicut Ipse contestatus est: «Nisi comederitis carnem Filii Hominis et Sanguinem Ejus biberitis, non habueritis vitam in vobis» $(\mathrm{J} 6,53)^{\prime \prime 56}$.

Patriarcha Venetianus hac occasione profundum magisterium de patriarchatis praesentat. Secundum Traditionem non pares ei sunt, quia:

- Romae Alexandriaeque archipresbyter est Papa;

- In Constantinopoli et Jerusalem - archiepiscopus;

Antiochiam omittit, quia huc scribit ${ }^{57} \ldots$

Patriarchati non multi debere esse, solum quinque, quia tanti sunt sensus hominum $^{58}$. Caput enim Mystici Corporis, multis membris compositi, semper Christus est.

Qua de causa tamen ,archiepiscopus Constatinopoleos” titulum patriarchae

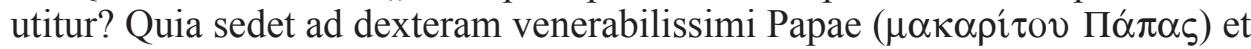
simili modo quam primo diacono titulus archidiaconi datur, ita primo post $\mathrm{Pa}-$ pam Romanum episcopo titulus Patriarchae reservatur. Haec situatio permittit ei atque docere et bona consilia dare. Non est enim possibile sextum patriarchatum creare.

Fideles vestri, sanctissime Orthodoxorum patriarcha frequenter malelau-

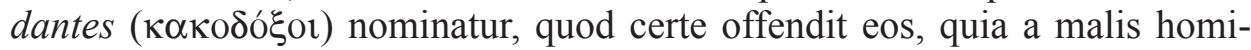
nibus affluit, dum declaratio patriarchae de Lido maxime positiva Orthodoxisque aperta est. Hoc debet confirmare praesentatam supra opinionem Epistolae, quia doctrina Orthodoxorum recta, acceptabilis aliis atque Christianis

${ }^{54}$ Patriarcha dicit hic de sancto Petro, qui initiator fuit existendi patriarchati Antiochenis, ipsum quem Ecclesia Occidentalis putat esse initiatorem existentiae Sedis Apostolicae.

${ }^{55}$ Epistola Dominici 1, PG 120, 752. Non debemus tractare hanc proclamationem in ironico sensu, hoc documentum est enim testimonium epoches cum omnibus ejus conditionibus, mentalitate, traditione, theologica methodologia... Ideo non est certe scriptum polemicum.

${ }^{56}$ Ibidem, PG 120, 753.

${ }^{57} \mathrm{Cf}$. ibidem 3, PG 120, 757. Animadvertemus raram in reflexione scientifica explicationem situs quinque Patriarchatorum: quattuor in Oriente, unus in Occidente...

${ }^{58}$ Cf. ibidem 4, PG 120, 753. 
est. Ambo ceterum Ecclesiae hereditates sancti Petri ac Pauli sunt. Et quo ab Apostolico datum et manibus cordibusque eorum ad perfectionem conductum, vere pietati serviendum est.

In monstrata expositione non deest sublima diplomatio aut cura de conservatione rectae relationis inter Orientem et Occidentem. Videtur tamen, quia „moderata positio partum conflicti" non de bona voluntate participantium facta, sed de contextu historico: in meridiana Europa Normani timorem excitabant $t^{59}$.

Normani, populus nordicus, disponabant enim excellente arte struendi navium, assicurantium iis longae expeditiones adeo ad Grenlandiam ${ }^{60}$ Islandiamque. Eorum possibilitates practicae permittebant iis novas regiones recultivare, et eorum pugnabilitas - ad statum equitum conduci. Hic status saeculo decimo inter eis initiatum est ${ }^{61}$.

Verum est, quia illo tempore activitas Normanorum finitur in Normandia (Rouen), sed non id significabat, quia Europa traquilliter vivere potuit, praesertim cum in hac regione creata erat fortis ,congregatio equitum Normanorum", quae jam dirigebatur mediaevalibus principiis codicis honoribilis et alta qualitate vitae spiritualis.

Sed hi equites semper in memoria tanebant repraesentantes status defensorum (offensorum?) esse, ideo in brevi tempore novam expeditionem deliberaverunt, eorum Victoria super Angliam commemorata, cujus Gulielmo Conquestore duce annexionem fecerunt. Bene exercitatus militium exercitus contra Siciliam motus est. Dux eorum Robertus Guiscardus ${ }^{62}$ (circa 1016-1085) erat.

Hic filius de Normandia equitis, anno 1046 servitionem suam initiavit simul cum fratribus contra Byzantium, aes militare Lombardis pagantibus, bellum gerens. Post mortem vetustiorum fratrum, anno 1057 dux conquerentium meridianam Italiam militum Normanorum factus est. Anno 1059, in Melphi synodo, foedus cum Papa Nicolao factus, suam servitionem vasalim ei proponit. Annis currentibus Calabriam occupavit, non multis annis fortitudinem hereditatibus suis gerens, Byzantinam Siciliam attingit, ubi de societate locali cum gaudio acceptatus est.

Securitas Europae ita majus illo tempore incerta erat, quia periculorum existentia adjuvata generali situatione ecclesiastica videbatur. Hostilis habitus Caesaris Germanici Henrici Quarti obligavit Gregorium Septimum papam ad concordiam, factam cum Roberto anno 1080. Hic factus clare permisit facilem

${ }^{59}$ Informationes de Normanis secundum meum novum, ad editionem praeparatum librum $\mathrm{Hi}$ storia Ecclesiae Orthodoxae in Graecia, p. 68-70 (manuscriptum, proprietas Auctori).

${ }^{60}$ Nota bene, illo tempore Grenlandia erat florens insula, nulla glacie coperta. Hyperglacialis periodus cathastrophicum initium in XVI saeculo habebat.

${ }^{61}$ Defensiva dimensio hujus status praecipue in relatione ad Sedem Apostolicam et ad mulieres videbatur. Quod refertur Apostolicae Sedi, non solum ordines equitum agebantur in exemptione, id est sub sola directione jussuum Papae, quem omnis equites de natura rei debeant defendere. In lumine hoc modo intelligibili traditione, actio Roberti videtur minime „misclarum”.

${ }^{62}$ Gallofrance Guiscardi nomen ,astutus”, „expertus” significat. 
viam equitis hujus ad sedem Caesaris Byzantini. Normani nam brevi tempore jam in Thessalia videbuntur.

Hoc periodo principalem partem ludit Argyrus (1000-1068), Lombardus gentilis generalisque Byzantinus, filius heroici Lombardi Melos, qui post perditam bataliam sub Cannae (1018) cum familia sua ad Constantinopolem capto bellico transportatus et ad carcerem designatus. Post annos viginti Apuliam revenit, ubi vi debitus in invasione Byzantina contra Siciliam participit.

Pro heroico ejus habitu seditionis contra Byzantinos in meridiana Italia comprimendi tempore, Caesar Constantinus IX dignitatem capitani Italiae eum nominat.

Ad bonam comprehensionem facti hujus rememorandus dualis character potestatis capitani (katepani - sic, originalis versio) est: haec erat simul militaris, conjuncta cum actionibus Caesaris, ac administrativa, magis separata.

Dux astutus occasionem bene sentiens, pro Papae Leonis IX intentionibus (qui postulabat totalem dimotum Normanos, radicem omnium malorum, de Apenina Peninsula), mediator Ejus cum Caesare factus ad foedus cum iis conduxit, bellum contra Normanos instigans.

Tamen pro simili foedere anterius facto, deleto tote iconoclasmi tempore, patriarcha Michael Caelurarius acerbis verbis contrastetit belli propositionem.

Quamquam, anno 1053 proba communis expeditionis facta est, quae tamen specialiter militibus Papae calamitas militaris videbatur, ipseque Papa post perditam bataliam in Civitavecchia Normanis ad servitudinem captus est.

Habitus Argyri in contexto eventorum anii proximi perplexus videtur, quamquam possumus de eo auscultare frequenter, quia in scriptis epochae notus est. Verisimiliter contactus cum legatis Papae, qui in vinculis manebat, volens participare in probis concordialibus, iis recommendationes suas dedit ut simul Constantinopolem adveniant.

Inaspectatum gerendum ejus animadvertit episcopus Petrus Theopolitanus, futurus patriarcha, epistolam ${ }^{63}$ ad Michaelem Cerularium scribens:

„Quanta inimicus maligne perpetraverit in sancto tuo ${ }^{64}$, quamque versutiam excogitaverint qui oderunt te ${ }^{65}$, levantes caput in medio tuae Ecclesiae, abunde docuerunt nos sacra litterae tuae, divinissime sancte domine ( $\theta \varepsilon 0 \varepsilon \imath \delta \varepsilon \sigma \tau \dot{\alpha} \tau \varepsilon$ $\delta \varepsilon \sigma \pi$ ó $\tau \alpha)$. Et magna nos hoc in re tenuit admiratio, qui non valeamus intelligere, unde motus aut quid volens Italus Argyrus, tantopere deflererit a via ${ }^{66}$ et sacra invaserit, homo non sacratus. Quid enim, inquit, commune cani et balneo $^{67}$, ut ille laicorum numero constitutus, sacerdotum negotus sese ingerat et scripta ejusmodi, sicut significasti falsa excogitet atque conficiat? [...]. Idque,

${ }^{63}$ Epistola Petri Theopoleos, totus orientis patriarchae dissertatio, eo tempore scripta, qua advenit Italus Argyrus ut nostra reprehenderet, PG 120, 785-816.

${ }^{64}$ Templum Hagia Sophia.

${ }^{65}$ Patriarcham Michaelem.

${ }^{66}$ De Constantinopoli ad Italiam Meridianam.

${ }^{67}$ Verisimiliter proverbium Byzantinum. 
cum papa vitam cum morte commutarit, verum sit Deo gratia, qui comprehendit sapientes in astutia eorum $(1 \text { Cor } 3,19)^{968}$.

Attamen, sicut videtur, rapida praesentia Argyri in sede Caesaris nimis patriarcham Cerularium peragitavit:

„Numquam diabolus absistit insidii contra nos et machinis adversus genus humanus, beatissime, sed subinde varias in vitam excitat calamitates et innumera quotidie contra homines commoverent commenta, per ea omnino nos quassare ac dejicere moliens. [...] Nunc vero postquam tum amota sunt mandata, tum orthodoxae fidei fontes copiose et ubertim ad fines terrae defluunt: homines quosdam exsecrandos, impios! [...] [Atque homines quidam] a papa missos se esse, verum Argyrii dolosis suggestionibus cinsiliisque ad imperialem urbem venerunt, ubi ingentium scandalorum causas tam in aliis quam adversus ipsam pietatem dare conati sunt"69.

3. Eucharistia fundamentum ecclesialis unitatis. Prius quam sopra scripta eventa facta sunt, atque ,pars Romanocatholica” probas concordiae geruit. Cognitus jam nobis, quamquam anonymus Patriarcha Venetianorum, praeferens unitatem in diversitate et harmoniam in multitudine, non haesitat tamen verba acuta dicere: Tacere non possumus auscultans, quia sacerdotes Constantinopoleos contemptionem adversus Ecclesiam Romanam habere solent (ỏveı $\delta^{\prime} \zeta \varepsilon \sigma \theta \alpha \imath$ ). Fons ,contemptionis hujus” et atque magnae litis erat quaestio materiae Sacramenti Eucharistici, id est qualitas usi in hoc sacramento panis.

Sacramentalis contextus permittit responsum alio modo generare, quam priores doctores facere solebant. Assertant nam ipsi, quia controversiones inter Orientem ac Occidentem creavit problema panis azymorum (in Occidente) et panis fermentati (in Oriente), attamen hae controversiones magnae non erant et significabant non multe.

Rationem habent tamen, sicut videtur, ii, qui profundum theologicum sensum in discussionibus monstrant: hae discussiones tetigit jam problema Sanctissimi Sacramenti, fontis principalis Salutis, fundamenti ecclesialis unitatis, et quod gravius, ,substantiae” existendi visibilis dimensionis Ecclesiae, quae agitur modo sacerdotis hujus mundi et totae naturae, semper tamen in contextu Invisibilis Societatis Hominum Salvatorum.

Existentia societatis Ecclesiae miraculum videtur, quia haec societas est ipsa Corpus Christi, ubi Salvator in suis membris sic manet, ut ii maneant in $\mathrm{Eo}^{70}$. Hoc modo Invisibile concretisatur in Visibili, sacramentali ac vero Corpore Domini, in cibo Aeternitatis. In hoc contextu quaestio qualitatis Panis insignificans non videri posset.

\footnotetext{
${ }^{68}$ Epistola Petri Theopoleos, PG 120, 796.

${ }^{69}$ Cerularius, Epistola secunda ad Petrum, patriarcham Antiochenum, PG 120, 816.

${ }^{70}$ Cf. A. Schmemann, Eucharystia, Białystok 1997, 16.
} 
Eucharistia est atque symbolum unitatis in una, sola Ecclesia, ideo authentica videtur declaratio Patriarchae Venetorum:

„Ubi nos unitatem Catholicae Ecclesiae servare, sive quolibet schismatice cupientes, maxime azymorum consuetudinem, non solum apostolica, sed ipsam Domini retinemus traditionem. [...] Nam fermenti et farinae commistio, qua Orientis utuntur Ecclesiae incarnati Verbi declarat substantiam, simplex vero massa azymarum, quam Romana tenet Ecclesia, puritatem humanae carnis, quam placuit divinitati sibi unire, citra controversiam repraesentat" $"$.

Caput hujus Corporis est Christus, sua castitas indubitalis est. Sed membra taliter multa? Hae peccabilitate characterisantur, sunt enim impura, nullo modo tamen influens Sanctitati Capitis. Caput Ecclesiae, Christus, est supra naturam membrorum, id est hominum et integram mundi naturam.

Ideo orientalis praxis uti panem fermentatum patriarchae de Lido non placuit: se Orthodoxi de Christo suam praxim acceperunt, qua de causa contra Eum et contra suos Patres Ecclesiales, qui assertabant materiam Eucharisticam panem azymorum et non fermentatum esse, agunt? ${ }^{72}$

Patriarcha Cerularius obstupuit hanc situationem videns, certus enim erat Orthodoxiam veram magisterium de Trinitate tenuisse, simul ac de Incarnatione Salvatoris nostri, Jesu Christi. Ideo consultum committenti dedit: in uno tamen claudicas, id est in quaestione panis azymi, quod est ei discordialis doctrina ${ }^{73}$.

Usus panem azymum de catholicis Romanis cum Traditione Veteris Testamenti colligitur; azyma tamen non solum huic Traditione sunt, sed ante omnia usata de Christo materia sacramenti erant, Qui suam Ultimam Coenam et primam insaguinabilem oblationem in Coenaculo obtulit, hoc modo sensum paradygmati eucharistici mundo aperiens. Haec materia eucharistica omnibus Hebraeis cognita, de natura rei fundamentum Oblationis Gloriae Novae factum est. Hebraei antiqui in azymis signum Providentiae viderunt memorationemque fugae de Egypto, signum spei miraculorumque Exodui accompanentium. Ideo, qui Coenae Eucharisticae participat, eo ipso atque azymis Foederis participet.

Tamen patriarcham Cerularium hac assertatio non persuasit. Azyma erant nam ei materia morta, animaque privata, quomodo ideo poterint ea materia Novae Paschae fieri? Solum farina et aqua addita possunt Corpus Christi gerere! Frustra Venetianus revocatus ad romanocatholicam theologiam est, frustra omnipotentiam Dei - Christi monstrabat. Patriarchae Cerulario oblatio semper opus Spiritus Sancti erat, Qui ante sabbatum sanctificavit oblationem Missae et Crucis. Tres enim viventes sunt, dans vitam communicantibus: Spiritus, Aqua et Sanguis (cf. 1J 5, 8) ${ }^{74}$.

\footnotetext{
${ }^{71}$ Epistola Dominici 3, PG 120, 753.

${ }^{72}$ Cf. ibidem.

${ }^{73} \mathrm{Cf}$. Cerularius, Epistola ad Joannem Tranensem in Apulia sive ad ipsum papam Leonem IX (latinisata cardinale Humberto, episcopo Silvae Candidae), PG 120, 763-764.

${ }^{74}$ Cf. Epistola Dominici 9, PG 120, 764.
} 
Praesentatio controversionum illo tempore scripto documento res gravis videtur. Scripta nam antiqua facilior adjutorium nobis dabunt ut melior intelligamus fundamenta discussionum, consensus rationes et viam ad eum. Eucharistia enim spatium vitae Ecclesialis est et meditatio super eam permittit plenius ,duobus pulminibus Orientis ac Occidentis perspirare”.

4. Anathema in controversione. Eventa descripta cacumini eorum cum adventu legatorum Papae attetigerunt. Ipsi legati voluerunt praesentare negativum habitum Apostolicae Sedis, quamquam Leo IX jam mortuus erat.

In dispositione eorum documentum papale erat, quasi bullae excommunicantis, de facto epistola centesima, monosignificanter auctoritatem Orthodoxiae deprimens ${ }^{75}$.

Principaliter Papa accusat Orientem pro scandalis, dum quasi omnis pagina Bibliae nos de pace admonet et ad tranquillitatem invitat. „Fratres et coheredes mei, relinquo vobis ex patrimonio vestro sortem, temporalem videlicet pacem", pacem integram et incontaminatam ${ }^{76}$.

Digne ideo confundetur haeresio impia, quae demolitur hanc insecabilem et indivisibilem unitatem Ecclesiae. Discedet ergo omnis perfidus corvus, omnes milvi, vultures! Sola columba ad aream redeat, et super caput Domini Jesu manens, totam tute unificabit Ecclesiam ${ }^{77}$.

Ecclesia sola enim semper una vocatur, id est numquam dividitur aut secatur. Semper perfecta, hoc est plena, numquam minuitur aut evacuatur. Semper immaculat, numquam corrumpitur aut maculatur ${ }^{78}$.

Splendida, quasi idealis imago Ecclesiae magis quam prior paesentata admonet ad unitatem magisque hanc unitatem characterizat. Semper-numquam, controversio - concordia fideles membra perfectionis, id est pleromae, creant. Simili modo, omni haeretico astuto et sine plena dignitate Christiani contra hanc pleromam stante, solum corvi nomen dignus est, in nullo tamen casu nomen columbae.

"Qui enim pectus columbae, velut humores mali solebat premere et ad nauseam jugiter provocare, alicujus accessionis vel occasionis impulsu egressi, vel ejecti $[\ldots]$ comprobantur eam relevare" 79 .

In conspectu Papae omnis Orthodoxus non solum superbus arrogansque est, sed factus membrum Antichristi praecursorque ejus effecti non cesset ,zizaniorum pestes in medium tritici spargere et messem, cum caeleste praeparatum horreum, quantum in eo est, atterere" ${ }^{80}$.

\footnotetext{
${ }^{75}$ Cf. Leo IX, Epistola 100. Ad Michaelem Constantinopolitanum, PL 143, 744-769.

${ }^{76}$ Cf. ibidem 1, PL 143, 744.

${ }^{77}$ Cf. ibidem 3, PL 143, 745.

${ }^{78} \mathrm{Cf}$. ibidem.

${ }^{79}$ Ibidem 4, PL 143, 746.

${ }^{80}$ Ibidem.
} 
In papali oratione non absunt accenti eschatologici. Michael Cerularius, ad quem scribit, signum enim est ,ultimae horae”, quae premonstrat adventum antichristi. Periculosum tempus, pejus omnium advenit, cum multi antichristi, id est patriarchae orientales agere voluerunt ${ }^{81}$.

Ecclesialis dimensio magisterii Papae divitior quam prior descripta imago videtur. Ecce cui haeresi similis est Orthodoxia:

„Quemadmodum enim Simoniaci donum Dei vendunt,

Ut Valesii hospites suos castrant et non solum ad clericatum, sed insuper

ad episcopatum promorent;

Ut Ariani rebaptizant in nomine Sanctae Trinitatis baptizatos Latinos

Donatistae decernunt extra Graecorum Ecclesiam Christi;

Ut Nicolaitae ${ }^{82}$ carnales nuptias concedunt" ${ }^{83}$.

Non desunt atque ,accusata graviora”:

- Mulieres vel in menstruis, vel partu periclitantes communicare non volunt, impuram sentiens;

- Comam capitis et barbam, veluti Nazareni ${ }^{84}$ nutrientes, non radunt ${ }^{85}$. In consequentia solum anathema debeat finire hanc epistolam. Ecce ejus verba:

„Quare non ejusdem sanctae et primae apostolicae sedis insignem injuriam, et vim non ferentes, et catholicam fidem multis modis demergi posse suspicantes, praejudicatione sanctae et individuae Trinitatis, et throni apostolici, cujus nos sumus apocrisiarii, et omnium orthodoxorum patrum, et septem synodorum, et universa Catholica Ecclesia anathemati, quod Dominus noster, piissimus Papa eidem Michaeli et illius sequacibus, si suaderi nolunt, decrevit, hunc in modum subscribimus" $"$.

Hac epistola accepta, Patriarcha Cerularius simul iratus et tremens est. Sentiens omnia pessima, scripsit ad Petrum, episcopum Antiochiae, quia illo tempore apparerunt in Constantinopole „seniores de Roma”, plenipotentiam habentes, de Papa docti, Orthodoxiam male cognoscentes. Statim post adventum suum ad unionem fidei inducebant, contra Francos ad expeditionem nos adhortabantes. Hoc audiente hanc epistolam simul cum ejus transvectione in Graecam reddimus Imperatori ut post assignationem nobis reddatur ${ }^{87}$.

\footnotetext{
${ }^{81} \mathrm{Cf} .1 \mathrm{~J}, 2$. In memoria teneamus: Apostolus Joannis amabat et semper revelabat Deum ỏ $\gamma \alpha \dot{\alpha} \pi \varepsilon v . .$.

${ }^{82}$ Nicolaitae - secta commemorata jam in Novo Testamento, cujus fundator Nicolaus de Antiochia probabiliter erat, (unus de Septem, solus non judaica origine); secta gnostica. Carnales nuptiae modus erat realisationis principii Nicolaiti: exerci carnem.

${ }^{83}$ Leo IX, Epistola 100, PL 143, 744.

${ }^{84}$ Nazarenus - persona votata Deo, quae nullam ,artificialem hygienam” observat, secundum principiis Nazareati.

${ }^{85}$ Cf. Leo IX, Epistola 100, PL 143, 744.

${ }^{86}$ Ibidem, PL 143, 744D.

${ }^{87}$ Cf. Cerularius, Epistola ad Petrum de Antiochia 3, PG 120, 784.
} 
Traductorem epistolae hujus peritus est cognitus jam nobis Argyrus, qui in brevi tempore opus suum ad finem, non tote bene adduxit, non gratiarum actionem Patriarchae sed ironiam ejus meritus est. „Magnus hic magister dixit Patriarcha - fidelis religioni suae, qui male sentit de Urbe et Imperio [Byzantino], atque hoc casu mores suas conservans pecuniam accepit, sibimet eas destinandas" $" 88$.

Hoc facto Argyrus contentus non est - in brevi tempore atque cum legatis quasi synodum convocat ${ }^{89}$. Advenientes hierarchae secundum Michaelem parva significatione erant, et unus eorum atque dignitate sua privatus est banitionique in quinque annis datus ${ }^{90}$.

Descriptio reliquorum eventorum de 16 die mensis julii AD 1054, papae jussu, cardinale Humberto in opere ejus Brevis et succinta commemoratio ${ }^{91}$ publicata, cognita est omnibus.

Generalis cogitatio theologorum Orthodoxiae super descripta facta, belli actum videre vult. Nonnulli eorum affirmant anathema non contra Orthodoxiam jactum est, sed contra patriarcham ac Caesarem et eorum sequaces. Factum est, quia argumenta contra erant acerba nimis et simpliciter potuerunt offendere personas, quae non imaginabat sibi consequentiones agendi. Sed... Rememoratas in initio articuli apocrisiario Petri et Patriarcha Constantinopoleos subscriptas Declarationes, controversiones alia luce revelant...

\section{NATURE OF THE ECCLESIASTIC UNITY AND 1054 EVENTS}

\section{(Summary)}

This article above could be called as a supplement to the History of the Church - it has been written not to present in a narrative way the common-known course of the East-West Schism which began in the $11^{\text {th }}$ century, but to give some remarks and to present some little known details, which could be helped to create a new dimension of reflexion, and even of discussion on problems included in this article.

The event of the $1054^{\text {th }}$ in modern historiography are treated as absolutely end of the "Church unity indivisibility period". This point of view does not divide the Author of this article, so he decided to present a new- quality-reflexion, thanks of it the described events could be recognized as the consequence of earlier revealing trends.

\footnotetext{
${ }^{88} \mathrm{Cf}$. ibidem.

${ }^{89}$ Legitime fecit, partiarcha ens et baptizatus.

${ }^{90}$ Cf. Cerularius, Epistola ad Petrum de Antiochia 5, PG 120, 785. Informatio videtur non tote rectam...

${ }^{91}$ Cf. Humbertus de Silva Candida, Brevis et succinta commemoratio, PL 143, 1001-1004.
} 
The Author also shows, that the Church unity is not so clear, because in the Church History you can meet some separatist tendencies. It is but very important, that no one of them could foil the principal ecclesiastical hallmark, the Unity. This Unity could situate the reality of Church in the God's Plan of Salvation, making it independent from human decisions, disagreement cases or arrogance.

The unity reflexion based both on the biblical and patristic analysis, permit us in new way treat the events of $1054^{\text {th }}$. Their "schismatic" character, especially in context of the patristic texts seems to by rather a heated discussion, in which both interested parts desire in cooperation to respond their epoch challenge. It was, after all, the great epoch of the Gregorian Roman Catholicism reform and of "theological Byzantine golden age".

So it should be better, when we treat the Schism simple as a division, and in the rough Hierarchy's declarations we find signs of Church responsibility. This way of thinking is justified by creating Normans' power and increasing problems with Caesaropapism tendencies.

The conclusion of this article is clear: in consequence of the $1054^{\text {th }}$ events "Byzantine Golden age" was about to be broken, but the Church Unity remained untouched...

\section{NATURA JEDNOŚCI EKLEZJALNEJ A WYDARZENIA ROKU 1054}

\section{(Streszczenie)}

Niniejszy artykuł ma charakter uzupełniający, nie został więc napisany celem narratywnego przedstawienia powszechnie już znanego przebiegu Wielkiej Schizmy Wschodniej, lecz aby przy pomocy kilku uwag i ekspozycji kilku mniej znanych szczegółów umożliwić nowy wymiar refleksji, a może wręcz dyskusji nad zagadnieniami, stanowiącymi treść niniejszej pozycji.

Wydarzenia roku $1054 \mathrm{w}$ historiografii uchodzą za jednoznaczne zakończenie „okresu niepodzielnej jedności eklezjalnej”. Celem więc niniejszego artykułu była refleksja nad jakością tej jedności i konstatacja, iż opisane wydarzenia można uznać za konsekwencję tendencji obecnych już wcześniej.

Z drugiej wszakże strony Autor wykazuje, iż jedność Eklezji to nie brak tendencji separatystycznych, lecz że nie są one w stanie zniweczyć tego jednego z najistotniejszych znamion rzeczywistości eklezjalnej, jakim jest jedność. Sytuuje ona Eklezję w Bożym Planie Zbawienia, uniezależniając ją od ludzkich decyzji, od przypadków niezgody czy pychy.

Refleksja nad jednością, poparta analiza biblijną i patrystyczna, pozwala też w inny sposób odnieść się do wydarzeń roku 1054. Ich „schizmatyckość” w świetle tekstów z epoki, jawi się raczej jako gorąca dyskusja obu zainteresowanych stron, które pragną wspólnie, w sposób duchowy odpowiedzieć na wyzwania ich epoki, epoki reformy gregoriańskiej po stronie rzymskokatolickiej czy „złotego wieku Bizancjum”, także teologii zapewniającemu odpowiedni rozwój.Można więc uznać, iż lepiej nazwać „Schizmę” po prostu podziałem, 
a ostre wypowiedzi hierarchów uznać za wyraz troski o właściwy kształt Eklezji, zwłaszcza w kontekście rodzącej się potęgi Normanów czy narastających tendencji cezaropapistycznych.

Autor nie ukrywa w konkluzji, iż na okresie „złotego wieku Bizancjum” pojawiła się pierwsza, poważniejsza rysa, jednak jedności kościelnej nic nie jest w stanie naruszyć...

Key words: the Church History, the Orthodox Church, Ecclesiology, Great East-West Schism.

Verba - claves: Historia Ecclesiastica, Orthodoxia, ecclesiologia, Grande Scisma Orientale.

Słowa kluczowe: Historia Kościelna, Prawosławie, eklezjologia, Wielka Schizma Wschodnia.

\section{BIBLIOGRAPHIA}

\section{Fontes}

Cerularius, Epistola ad Joannem Tranensem in Apulia sive ad ipsum papam Leonem IX (latinisata cardinale Humberto, episcopo Silvae Candidae), PG 120, 755-782.

Cerularius, Epistola ad Petrum de Antiochia, PG 120, 781-796.

Cerularius, Epistola secunda ad Petrum, patriarcham Antiochenum, PG 120, 815-820.

Epistola Dominici patriarchae Venetiarum ad patriarcham Antiochenum, PG 120, 751-756.

Epistola Petri Theopoleos, totius Orientis patriarchae dissertatio, eo tempore scripta, qua advenit Italus Argyrus ut nostra reprehenderet, PG 120, 795-816.

Humbertus de SiLva CANDida, Brevis et succinta commemoratio, PL 143, 1002-1004.

Leo IX, Adversus Graecorum calumnias (false titulatum Dialogus inter Romanum et Contantinopolitanum), PL 143, 744-769.

Leo IX, Epistula 19, PL 143, 758.

Leo IX, Epistula 20, PL 143, 764.

Leo IX, Epistola 100. Ad Michaelem Constantinopolitanum, PL 143, 744-769.

Leo DE OchrIDA, Epistola ad Joannem Episcopum Tranesensem, PG 120, 836-838.

Nicetas Chartophylax Nicaenus, Quibus temporibus et quarum criminationum causa a Constantinopolitana Ecclesia sejunxerit se Romanorum Ecclesia, PG 120, 713-720.

\section{Gravissima elaborata}

GAY J., L'Italie Meridionale et l'Empire Byzantine (867-1071), Paris 1904.

HaLdon J., Warfare, State and Society in the Bizantine World 565-1204, Oxford 1999.

PrzeKop E., Rzym - Konstantynopol. Na drogach podzialu i pojednania, Olsztyn 1987.

Runciman S., Schizma Wschodnia, tłum. Jan Gawroński, Warszawa 1963.

Schmemann A., Eucharystia, Białystok 1997.

ТомсZак R., Eklezjogeneza w interpretacji wspótczesnych polskich teologów, „Studia Paradyskie" 16 (2006) 179-195. 
